\title{
Methodology to Identify and Quantify Sources of Process Scrap on Shop Floor
}

\author{
Duaa Alrufaihi, Audrey Fernandes, Bhavya Gangar Jaysukh, Pauline Goldery, \\ Rashmeet Kaur, Samuler Tirado Alvarez, Daniel Vazquez Navarro, Konstantinos \\ Salonitis ${ }^{*}$ \\ Manufacturing Theme, Cranfield University, Cranfield, MK43 OAL, UK \\ * Corresponding author. Tel.: +44-1234-758347.E-mail address: k.salonitis@cranfield.ac.uk
}

\begin{abstract}
Poor quality costs are the total financial losses caused by the products or services not being perfect. Process scrap is a major contributing factor to these losses. Identification of different sources of scrap and the resulting costs is paramount for Continuous Improvement. Furthermore, quantification of this scrap and how the data can be visualised will facilitate decision making by upper management. For this, a methodology that acts as a guide will prove to be of great use in the analysis of scrap generation in any manufacturing plant. In the case study presented, a comprehensive list of the possible sources was made. However, only those which were responsible for a major part of the cost and of great concern were shortlisted. Once identified, several measurement systems were proposed to accurately quantify the resultant scrap. This was then followed by data visualisation using a dashboard that gave a weekly update on the levels of scrap generated.
\end{abstract}

Keywords: scrap; sources of scrap; scrap measurement; cost of scrap; scrap visualisation.

\section{Introduction}

Companies strive to develop, produce, and provide competitive products or services that will meet and surpass customer needs, with low-cost and high-quality to enable competitive advantage [1]. To achieve this objective, the processes which products or services go through should be consistent and robust, so that customer satisfaction can be achieved. Previously, companies had the impression that high quality was equal to high cost, but later, it was realised that poor quality equals high costs [2]. To be able to continuously improve quality, companies need to be aware of scrap, as a consequence of poor quality, that arises in business operations as well as the resources needed to work on quality improvement.

Furthermore, to be able to quantify scrap, it is necessary to identify and measure its root causes for subsequent control and management [3]. Thus, the goal of studying scrap and its sources is to improve production processes and to alter these processes to reduce associated costs [4].

The sources of scrap could arise from multiple points in the process and associated machinery; hence it is a challenge to precisely measure and monitor regularly [5]. Given this challenge, a definite and well-tested methodology to implement the appropriate measurement system along with a comprehensive visualisation and monitoring tool such as a dashboard must be adopted in any organisation.

This research paper attempts to provide a systematic approach to identify the sources of scrap that arise in any manufacturing plant. Furthermore, the data obtained can be used to quantify scrap and further visualise it for decision making pertaining to scrap. This proposed approach is applied to a case study in order to check its feasibility wherein the overall production flow from receiving the raw material to assembly of the product is studied and a data collection method for estimating and verifying the scrap sources is developed. The approach described here can be extended to other companies.

\section{Literature Review}

\subsection{COPQ and its Components}

The term Cost of Poor Quality (COPQ) was introduced by J.M. Juran to create awareness about quality and quality improvements. COPQ includes all the costs associated with not producing an item perfectly in the first attempt [6].

COPQ consists of four components [6]:

- Internal failure costs: The costs associated with having defects in a product before it gets delivered to the customer.

- External failure costs: The costs of discovered defects after it has been shipped to the customer. 
- Appraisal costs: The costs related to the activities of inspecting and evaluating the quality of materials from the suppliers.

- Prevention costs: The costs associated with preventing defects or quality issues from happening such as the process of reviewing designs and verifications and training.

In practice, different quality costing models have been used by different organisations in different industries. They are: Prevention, Appraisal, Failure (PAF) model, Crosby's model, Opportunity or intangible cost, process cost, and $\mathrm{ABC}$ model [7].

However, the orthodox PAF model for quality cost notably underrates the cost of poor quality [8]. Hence, every organisation has its own understanding and definition of quality costing model. The components of quality costing model are chosen based on the company's business priorities and overall focus area of their strategic policies [7].

As process scrap is the focus area of this research, the category of COPQ it falls under, which is internal failure, is important to be noted.

\subsection{Internal Failure}

Internal failure costs come into picture when a defective product is produced and arises as the following [9]:

- In-process scrap and rework

- Maintenance and repair

- Design changes

- Additional inventory required to support poor process yields and rejected lots

- Re-inspection or retest of reworked items

- Downgrading

Internal failure can cost up to $90 \%$ of the sale price, as material and process cost is irrecoverable, and reworking is expensive. Such examples include cases of rubber and plastic moulding, rubber extrusion and steel tube bending, in these cases there is neither the chance of reworking nor the recycling of raw material and hence this gives rise to large amounts of process scrap. For the cases where reworking is possible and not costly, internal failure cost is on lower side and effectively the scrap produced is also low [10].

In order to realise these costs, the scrap needs to be measured.

\subsection{Measurement of Scrap}

Measuring scrap can be used to translate the effects of poor quality into financial terms in order to visualise it for the management and the employees, to make the employees cognizant of what the costs are [4]. By doing this, there is a greater chance that the management uses the measurement instead of rejecting it [11]. Companies must strive to find poor quality costs as early as possible to prevent re-work, scrap, and dissatisfied customers or lost reputation [12]. Furthermore, the use of scrap measurements will also provide the company with a tool to identify problem areas and to prioritize [3] and determine exactly where the potential improvements should be carried out [13]. Fig. 1 shows the visible costs that could be responsible for high levels of poor-quality costs, however, this is just the tip of the iceberg. The invisible part houses the more concerning factors that need investigation and measurement techniques to ascertain the exact amounts contributing to COPQ.

Measurement techniques need to address certain key elements in order for it to be effective and ensure easy implementation which include the reason for measuring the scrap, clearly stated responsibilities of personnel involved in measuring, its management and finally, its comparison for accurate assessments to identify crucial areas which affect the poor quality costs [5].

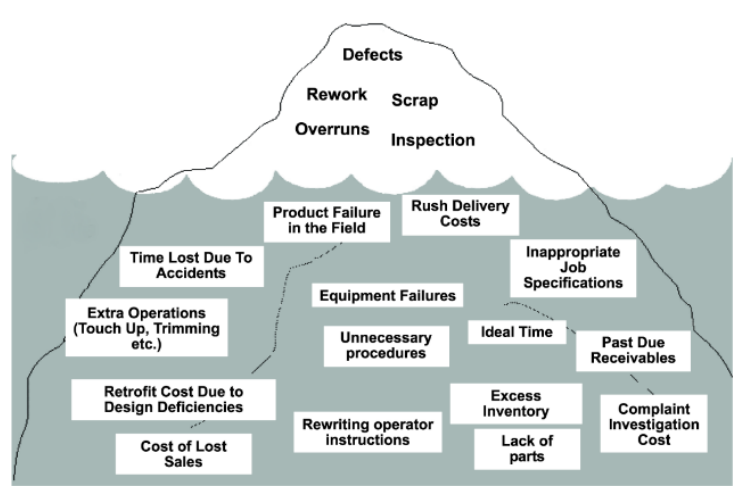

Fig. 1. Iceberg of Visible and Invisible Costs [14]

\subsection{Dashboard}

Once the scrap sources are defined and measured, it must be visualised comprehensively to enhance decisions. Therefore, a dynamic and intuitive dashboard will help serve this purpose. A Visual Dashboard visualises the actual data from an external data source(s). The term dashboard can be defined as a graphic display that consists of charts, maps and graphic indicators [15]. Others refer dashboard as "a graphical presentation of the current status (snapshot) and historical trends of an organisation, 'Key Performance Indicators (KPIs)' to enable instantaneous and informed decisions to be made immediately [16]." Moreover, it helps to evaluate the information and thereby allows the company to make correct decisions, improvise, and take any urgent action if necessary. In practice, before being 
visualised, the data needs to be first recorded, then stored and processed and finally analysed [17].

The above review provides a better understanding of what is COPQ and its components. Scrap falls under the category of Internal Failures due to production of defective products. Moreover, every company has its own method to calculate poor quality costs relative to their business. In addition, the need for measurement of scrap is highlighted followed by the need for visualisation of the scrap components as it is necessary for decision making, therefore a live dashboard is the best visualisation tool.

However, some gaps remain in the literature due to the sensibility of the scrap information. No specific measurement systems or case study and examples were found. This explains the absence of a common standard across companies to identify, quantify and visualise scrap. The literature review, however, highlighted the importance of granularity of the measurement system used.

\section{Developed Approach}

To have a guided approach, the Deep Dive is suggested as it is widely used for innovation in Process Improvement. It is devised as a combination of discussion, prototyping, and feedback loops merged into an approach that helps teams to develop solutions. The Deep Dive methodology helps demonstrate that it is known what is wrong, a thorough examination has been done and a solution for the issue has been come up with.

It consists of the following steps:

1. Understand: Without having a clear understanding of the problem, it is challenging to start problem solving. Interviews and Document Reviews are key tools.

2. Observe: To get clarity on the current systems in place, the observe phase is crucial as it allows for visual understanding of the processes involved. Gemba walks are highly suggested in for this.

3. Visualise: Visualisation of the interpretations helps in identifying key steps in the process and determining the critical components that need special attention. Maps are a useful aid.

4. Evaluate and Refine: Evaluation by the stakeholders plays an integral role in the refinement of proposed solutions to the problem at hand. Discussions and feedback enable for better evaluation.

5. Implement: Once the final idea is proposed, it is important to have a standard system in place followed by the visualisation of the outcome to facilitate decision making. A dashboard is a powerful tool for visualisation.

Fig. 2. Deep Dive methodology

\subsection{Scrap Source Identification}

To generate the necessary base for investigation while performing the analysis, an iterative document review and stakeholder interview-based method can be used to detect all the possible scrap sources.

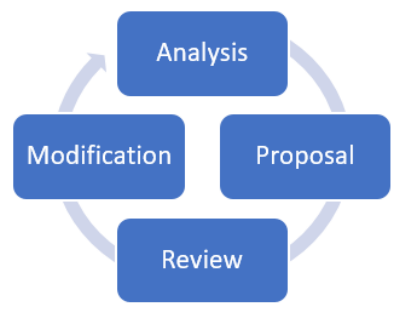

Fig. 3. Scrap sources iterative identification

A first analysis must be conducted to understand the process and nature of the scrap generation. To do so, the existing value stream maps, general operational procedure documents and previous process waste works must be analysed. Once a basic understanding has been built, a preliminary scrap source map should be drawn. All the possible scrap generation points must be identified and for each, a data collection method has to be proposed. The result of this phase is an initial scrap sources map which must be later validated. During the review process, interviews should be conducted with experts of the factory to validate the proposal and obtain feedback of all its relevant points. This will help in discarding the non-impactful sources and add the ones that were missed. Once every cycle is complete (see Fig. 3), the analysis phase consists of obtaining new documents and information sources, further broadening the possible sources' number and coverage of the process. The procedure ends when all the possible sources of information have been analysed, and the experts and stakeholders have validated the proposed solution.

The scrap sources can be map-based (E.g.: process flow charts, Swimlane diagram, data flow diagram) to provide an overview of how processes are carried out, how they can be improved and how many steps are necessary to drive the process to its end [18]. After initial process study and observation, a validated list of multiple sources of Process Scrap can be identified. 


\subsection{Scrap Quantification}

Once the process is understood, the precision, granularity and robustness of all the process waste should. A variety of measurement techniques presented in Table 1 need to be considered.

Table 1. Advantages and disadvantages of the proposed measurement methods

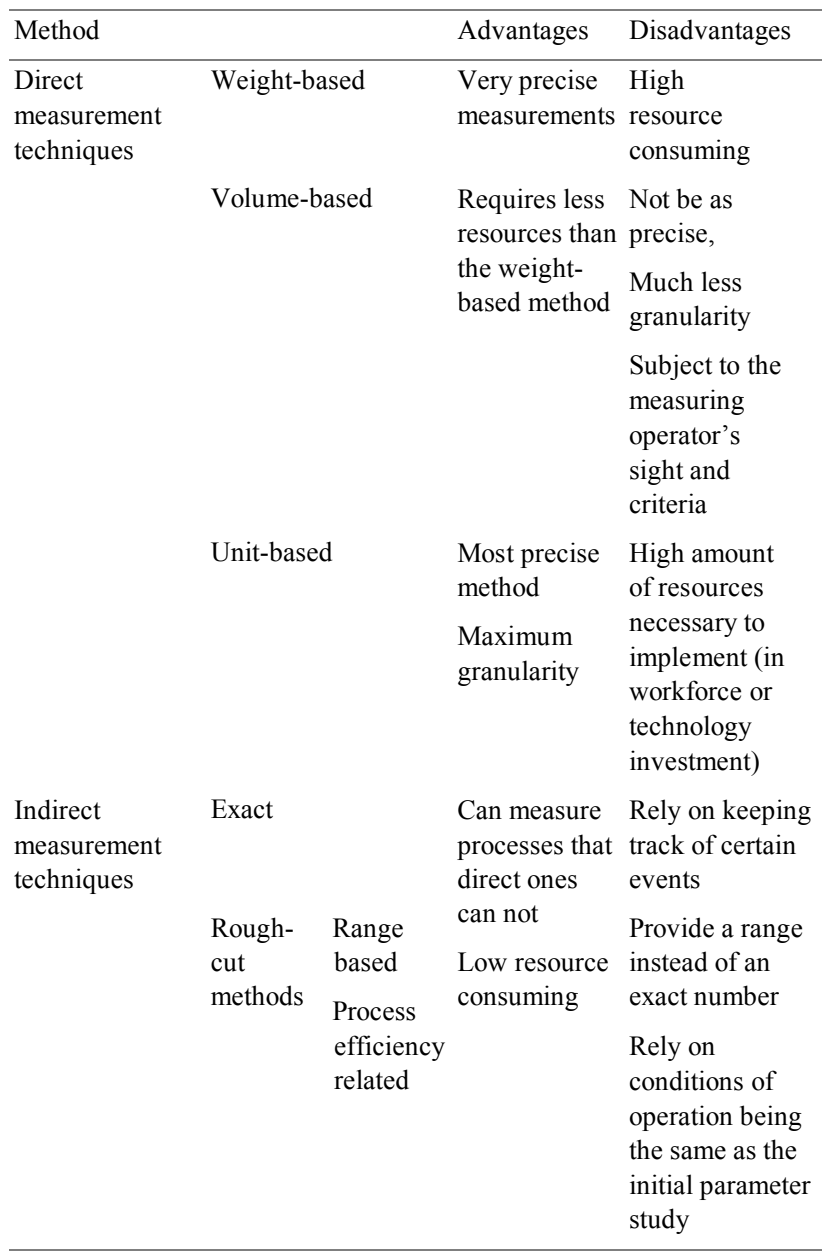

The following factors must be considered to narrow down and prioritize the top (5-10) Sources of Scrap and to implement the corresponding Measurement technique for them:

- Manpower and Manhours Requirements

- Existence of Current Alternative Solutions

- Possibility of Automation

- Ease of Implementation and Data Collection

- Perceived monetary impact by stakeholders

The measurement system has to be designed to achieve a balance between accuracy and workload increment for the company's associates. However, it can some possible flaws regarding the accuracy of the measurements. First of all, the proper record of the data will have a direct impact on the dashboard results and can reflect a false image of reality.
Additionally, for the new measurement systems proposed, a successful change management program to put them in place will be necessary.

The amount of scrap collected can be recorded either manually or automatically, depending on the warehouse managed system in place. This data will then be compiled in the backend and used to feed the process scrap dashboard.

\subsection{Scrap Cost Calculation}

To quantify the value of the scrap, three different methods are used depending on the type of scrap: raw materials, work in progress (WIP) or final parts.

To quote the scrap of raw materials equation (1) is used. The economic value (V) of a scrap type can be calculated as the amount of material scrapped (M) times the price of it (C), as shown in equation (1).

$$
V_{i}=M_{i} \cdot C_{i}
$$

Regarding WIP and final parts, other costs need to be included, such as labour costs, machinery costs. Good practices would forecast the annual demand (AD) to standardize the price of the manufactured component. Then the material component usage $(\mathrm{M} \cdot \mathrm{C})$, the annual costs of labour (AL), machinery amortization (AMA), maintenance (AM), overheads $(\mathrm{AOH})$ and other costs associated to the process $(\mathrm{O})$ are divided by the annual demand (AD) to homogenously distribute them as shown in equation (2).

$$
V=\sum_{i=0}^{n} M_{i} \cdot C_{i}+\frac{A L+A M A+A M+A O H+O}{A D}
$$

\subsection{Visualisation of Scrap}

After the identification and quantification of scrap, a user can find the cost of scrap on the shopfloor. This can be taken a step further with the creation of a dashboard to visualise the quantity, percentage and costs of scraps from the different sources. The following charts can be used to display different data types:

- Bar charts are very useful to quickly compare information, revealing highs and lows at a glance. They are especially effective when the data can easily be split into different categories [19].

- Pie charts are the most appropriate to show relative proportions for top level information.

- Pareto charts are the perfect combination of bars and lines to highlight the most relevant set of factors among a large set of them. 
- Line charts are primary used to display trends over a period.

These charts can be selected to trigger the appropriate management reflections and decisions that need to be made.

\section{Case Study}

\subsection{Presentation of the case study}

The company in which the proposed methodology was developed produces plastic moulded components. The study focused on a high-volume product line. The product composed of three components moulded in house, via injection moulding, and then assembled, with automated machinery. Therefore, the overall line, from receiving raw materials to final assembly was studied.

\subsection{Scrap source identification}

To get an overview of the whole process, process maps were realised after the first few Gemba walks. Diverse mapping tools were used, such as post-it notes, to get a quick overview of the process, flow charts, as represented in Fig. 3, along with Swimlane diagram, were also used to understand the actions of each department. Some sources of scrap were also identified during the Gemba walks.

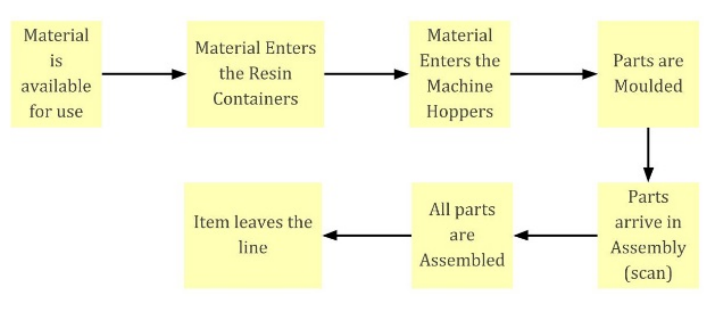

Fig. 3. Process flow chart

After this first step, interviews with the relevant stakeholders were conducted, to come up an exhaustive list of the scrap sources. These interviews were with operators, team leaders, quality managers, and the production manager. To ensure the reliability of the data collected, they were at least double checked.

In this way, 21 sources of process scrap were identified and then validated by different stakeholders and are listed in Table 2.

Table 2. List of scrap sources

\begin{tabular}{|c|c|c|}
\hline Scrap & Description & Areas \\
\hline $\begin{array}{l}\text { Material } \\
\text { Handling }\end{array}$ & $\begin{array}{l}\text { Material that falls from bags } \\
\text { while being handled }\end{array}$ & Storage \\
\hline
\end{tabular}

\begin{tabular}{|c|c|c|}
\hline Wrong resin & $\begin{array}{l}\text { Resin loaded in the wrong } \\
\text { container }\end{array}$ & Storage \\
\hline $\begin{array}{l}\text { Quality Control } \\
\text { Lab (assembly } \\
\text { samples) }\end{array}$ & $\begin{array}{l}\text { A fixed percentage is tested } \\
\text { and then scrapped }\end{array}$ & Storage \\
\hline $\begin{array}{l}\text { Machine } \\
\text { Automatic } \\
\text { Rejects }\end{array}$ & $\begin{array}{l}\text { Whenever there is non- } \\
\text { conformance with any of the } \\
\text { parameters of moulding }\end{array}$ & Moulding \\
\hline Purging & $\begin{array}{l}\text { Whenever they need to clean } \\
\text { the barrel }\end{array}$ & Moulding \\
\hline Stabilising & $\begin{array}{l}\text { Whenever they switch off the } \\
\text { machine for more than } 24 \\
\text { hours }\end{array}$ & Moulding \\
\hline Hoppers & $\begin{array}{l}\text { Material that falls from } \\
\text { hoppers and every time a } \\
\text { breakdown happens }\end{array}$ & Moulding \\
\hline $\begin{array}{l}\text { Visual hourly } \\
\text { inspection }\end{array}$ & Regular tests of quality & Moulding \\
\hline Parts Falling Off & Parts falling off the belt & Moulding \\
\hline Cavities Off & $\begin{array}{l}\text { The operator can switch off } \\
\text { fault suspected cavities }\end{array}$ & Moulding \\
\hline $\begin{array}{l}\text { Cleaning and } \\
\text { Maintenance }\end{array}$ & $\begin{array}{l}\text { They scrap on the beginning of } \\
\text { each shift } 10 \text { shots }\end{array}$ & Moulding \\
\hline $\begin{array}{l}\text { Material } \\
\text { Handling }\end{array}$ & $\begin{array}{l}\text { Parts dropped while the } \\
\text { material handlers move the } \\
\text { boxes }\end{array}$ & Assembly \\
\hline Parts Falling Off & $\begin{array}{l}\text { Parts dropped while the } \\
\text { machine is operating }\end{array}$ & Assembly \\
\hline $\begin{array}{l}\text { First Exit Plate } \\
\text { Rejection }\end{array}$ & $\begin{array}{l}\text { Non-conformance to } \\
\text { parameters }\end{array}$ & Assembly \\
\hline $\begin{array}{l}1^{\text {st }} \text { part Black } \\
\text { Particulate Test }\end{array}$ & $\begin{array}{l}\text { Checking for black } \\
\text { contamination }\end{array}$ & Assembly \\
\hline $\begin{array}{l}2^{\text {nd }} \text { part Black } \\
\text { Particulate Test }\end{array}$ & $\begin{array}{l}\text { Checking for black } \\
\text { contamination }\end{array}$ & Assembly \\
\hline $\begin{array}{l}\text { IPC (trigger test } \\
\& \text { visual } \\
\text { inspection) }\end{array}$ & $\begin{array}{l}\text { For every fixed amount of } \\
\text { products, they test some of } \\
\text { them }\end{array}$ & Assembly \\
\hline $\begin{array}{l}\text { Automatic Coiler } \\
\text { Rejects }\end{array}$ & $\begin{array}{l}\text { Non-conformance to } \\
\text { parameters }\end{array}$ & Assembly \\
\hline $\begin{array}{l}\text { Coiler Batch } \\
\text { Mode }\end{array}$ & $\begin{array}{l}\text { Scrap generated by coiler } \\
\text { when wire is changed. }\end{array}$ & Assembly \\
\hline Line Clearance & $\begin{array}{l}\text { Scrap generated every time } \\
\text { they change the line or at the } \\
\text { beginning of a Production } \\
\text { Order }\end{array}$ & Assembly \\
\hline $\begin{array}{l}\text { Checkback batch } \\
\text { fill-up }\end{array}$ & $\begin{array}{l}\text { Quality non-conformance } \\
\text { related scrap }\end{array}$ & Assembly \\
\hline
\end{tabular}

\subsection{Scrap quantification}

The prioritisation of the top 10 sources of scrap, according to the factors listed in section 3.2 resulted in the selection of the following scrap sources: Machine automatic rejects, purging, stabilizing, visual hourly inspection, parts falling off, cavities off, first exit plate rejection, $1^{\text {st }}$ part black particulate test, $2^{\text {nd }}$ part black particulate test, IPC and automatic coiler rejects. 
Each scrap source was then categorised, and a system was selected for each category, according to the following Table 3 .

Table 3. Measurement system selection for each main category of scrap source

\begin{tabular}{lll}
\hline Category & $\begin{array}{l}\text { Measurement } \\
\text { Technique }\end{array}$ & Rationale \\
\hline $\begin{array}{l}\text { Parameters Non- } \\
\text { Conformance } \\
\text { (Moulding) }\end{array}$ & Volume-Based & $\begin{array}{l}\text { Fewer resource } \\
\text { utilisation }\end{array}$ \\
$\begin{array}{lll}\text { Maintenance and } \\
\text { Inspections }\end{array}$ & $\begin{array}{l}\text { Exact Indirect } \\
\text { Measurement }\end{array}$ & $\begin{array}{l}\text { Ease of } \\
\text { implementation }\end{array}$ \\
& $\begin{array}{l}\text { Existing } \\
\text { complementing } \\
\text { procedures }\end{array}$ \\
Process & Range-Based & $\begin{array}{l}\text { Fewer resource } \\
\text { utilisation }\end{array}$ \\
Stabilisation and & Rough-Cut & \\
inefficiency & Calculation & Weight-based \\
Parrel Purging & Lack of alternatives \\
Non-Conformance & Unit based & Existing \\
(Assembly) & & measurement system \\
& & High accuracy
\end{tabular}

The data was then recorded manually (for the scrap in the moulding area, and the quality test samples) and automatically (for the scrap in the assembly area) into the warehouse managed system, as shown in Error! Reference source not found.

\subsection{Scrap cost calculation}

According to the recommendations of section 3.3, the cost of the different types of scrap generated was calculated depending on its category.

Equation (1) was used to evaluate the costs of purging and stabilisation waste. For the other parts scraped, their standard cost, established at the beginning of the financial year, was considered.

After extracting the scrap data from the system, it was automatically imported in an Excel file, where the cost of different types of scrap was calculated.
Fig. 4. Moulding area dashboard

\subsection{Visualisation of scrap}

To visualise the scrap, two software were considered: Excel and Power BI. The former was selected for various reasons, amongst which was the familiarity of the users of the dashboard. Three dashboards were realised with Excel Pivot Charts, to represent the overall scrap, and the scrap by areas of generation. Multiple slicers were also used, to enable the user to drill down the source of an unexpected result. As shown in Fig. 4 multiple graphs were selected consciously to trigger the appropriate management reflections and decisions.

However, this system works under the assumption made about the reliability and accuracy of the data provided by the assembly machines. This assumption has been made after several interviews with stakeholders who believed the data was accurate enough to use it.

\section{Impact on Through Life Engineering Cost}

While there will be cost savings through elimination of scrap at multiple sources, the measurement techniques proposed come with a cost of implementation. This trade-off is critical to decide whether or not to invest time and capital on this improvement project.

Through-life Engineering Services are the product support provided at different stages of its lifecycle. This encompasses the entire range of process starting from ideation, design, manufacture and operational life, to end of life disposal. They are seen as a natural stage in the evolution of product support and maintenance, repair and overhaul strategy [20].

The various cost components of Through Life Engineering Services can include: In-Service, Maintenance Cost Svctem I Inoradation Cost and

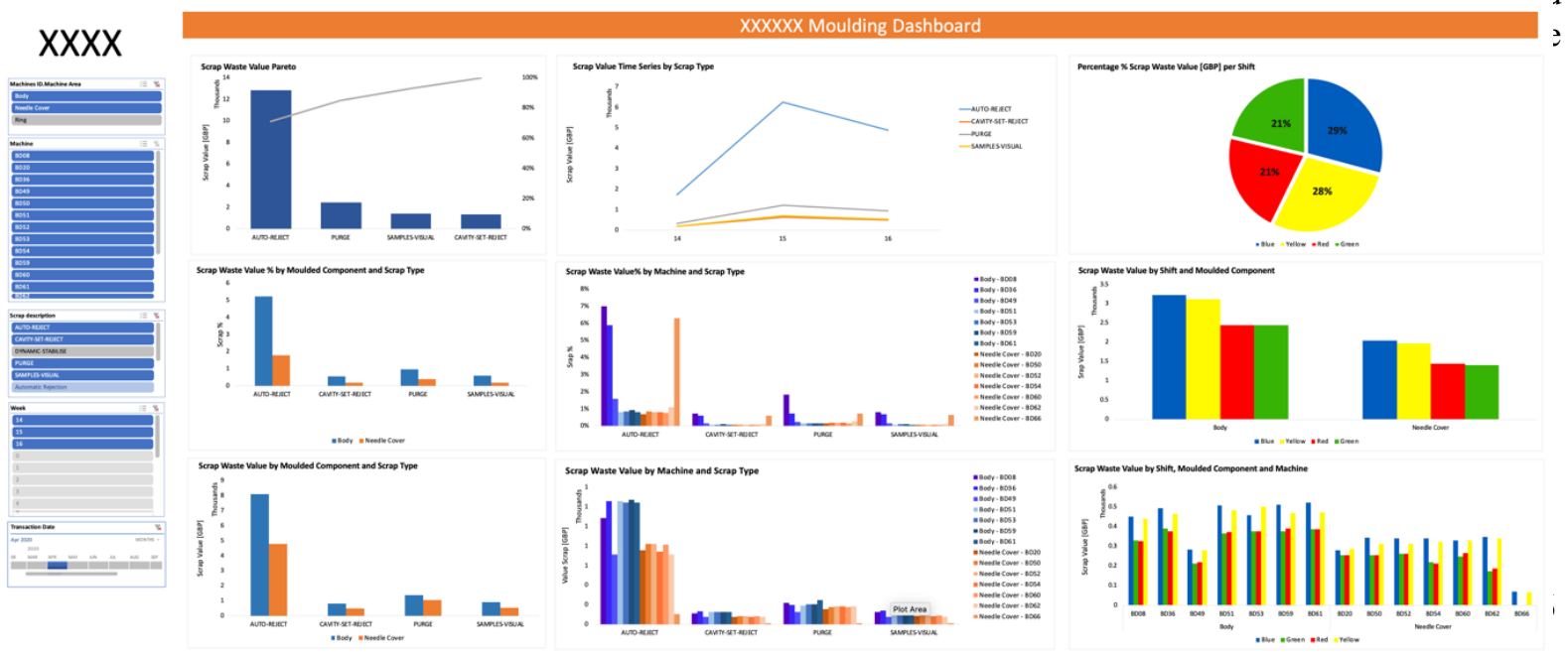


product life cycle.

Considering the measurement system as the product being introduced to the pre-existing manufacturing system, there will be some components of cost added into the system. These include:

\section{Service and Maintenance Cost}

This is the additional cost associated with maintaining the measurement systems that will be implemented. If the equipment and the implemented measurement system is not serviced and maintained regularly, the quality of data collection might go down. This will impact the accuracy of the complete measurement system.

\section{Training Cost}

The current associates and manpower will have to be trained to run the measurement system in order to collect data for visualization. Additionally, there will be cost associated with training the person in charge to collect scrap without mixing. The entire measurement system implementation will be null void in case the data gathered is not accurate due to human errors. The only way to eliminate or minimize these errors is training of personnel's which comes with a cost.

\section{Equipment and IT Systems Upgradation Cost}

The measurement system proposed relies heavily on scrap data collected from the shop floors. The quality and accuracy of data is indirectly related the availability of IT systems and affiliated equipment technology available to be used. In case there is a lack of enterprise systems or smart machines that can collect and record the data, there will be heavy investment need to upgrade the systems to that level.

\section{Conclusions and Recommendations}

In this paper, the deep dive methodology was utilised as a guide to identify, quantify and visualise the process scrap. An iterative approach (analysis, proposal, review and modification) was used to identify multiple sources of scrap. This approach led to the formulation of a holistic list, which was then narrowed down to the top 10 sources. For accurate quantification of this scrap, certain factors (such as manpower and manhours requirements, existence of current alternative solutions, possibility of automation, ease of implementation and data collection and perceived monetary impact by stakeholders) were considered. A variety of measurement methods were explored to accurately quantify this resultant scrap. In addition, these measurement systems were designed to achieve a balance between accuracy and workload increment for the company's associates. Furthermore, a dashboard was developed for representing the key metrics using graphs.

This developed approach can be used by any manufacturing plant in order to understand the source of scrap generation, system that can be put into place to quantify it as well as visualisation methods.

However, only the process scrap was measured. It is only one component of COPQ, and further investigation into the other sources of poor quality must also be considered for further improvement project.

\section{References}

[1] H. Alghamdi and C. Bach, "Quality As Competitive Advantage," Int. J. Manag. Inf. Technol., 2013, doi: 10.24297/ijmit.v8i1.690.

[2] B. Bergman and B. Klefsjö, Quality from customer needs to customer satisfaction, 3rd ed. Lund: Studentlitteratur AB, 2010

[3] J. S. Oakland, Total Quality Management - Text with Cases. 2003.

[4] G. H. Hwang and E. M. Aspinwall, "Quality cost models and their application: A review," Total Quality Management. 1996, doi: $10.1080 / 09544129650034837$.

[5] L. Sörqvist, "Effective methods for measuring the cost of poor quality," Measuring Business Excellence. 1997, doi: 10.1108/eb025484.

[6] B. R. Feiring, T. C. P. Sasfri, V. M. R. Tummala, and R. W. Mak, "Modelling the cost of poor quality in a five-state part manufacturing operation: A case study," J. Oper. Res. Soc., vol. 49, no. 12, pp. 1249-1253, 1998, doi: 10.1057/palgrave.jors.2600646.

[7] A. Schiffauerova and V. Thomson, "A review of research on cost of quality models and best practices," International Journal of Quality and Reliability Management. 2006, doi: $10.1108 / 02656710610672470$

[8] B. H. Eriksson, "Using cost of poor quality to identify areas for quality improvements," p. 97, 2016.

[9] A. Feigenbaum, "Total quality control," Harv. Bus. Rev., vol. 34, no. 6, pp. 93-101, 1956.

[10] S. N. Abbas, J. Ahmed, M. Salman, and S. R. Ashraf, "Compare Cost of Good Quality \& Cost of Poor Quality And Have a Wise Decision A study from Automobile Industry of Pakistan," IOSR J. Bus. Manag. Ver. II, 2015, doi: 10.9790/487X-17921928.

[11] J. Middle, “ A review of: 'Quality Costing' By Barry G. Dale and James J. Plunkett (Chapman \& Hall, London, 1991) [Pp. 169]," Int. J. Prod. Res., 1993, doi: 10.1080/00207549308956875.

[12] M. Gaudard and H. J. Harrington, "Poor-Quality Cost," Technometrics, 1988, doi: 10.2307/1270101.

[13] S. Roden and B. G. Dale, "Understanding the language of quality costing," TQM Mag., 2000, doi: $10.1108 / 09544780010326362$.

[14] S. K. Krishnan, "Increasing the visibility of hidden failure costs," Meas. Bus. Excell., 2006, doi: 10.1108/13683040610719290.

[15] M. Ji, C. Michel, É. Lavoué, and S. George, "DDART, a dynamic dashboard for collection, 
analysis and visualization of activity and reporting traces," Lect. Notes Comput. Sci. (including Subser. Lect. Notes Artif. Intell. Lect. Notes Bioinformatics), vol. 8719 LNCS, pp. 440-445, 2014, doi: 10.1007/978-3-319-11200-8_39.

[16] B. A. Schwendimann et al., "Perceiving learning at a glance: A systematic literature review of learning dashboard research," IEEE Trans. Learn. Technol., vol. 10, no. 1, pp. 30-41, 2017, doi: 10.1109/TLT.2016.2599522.

[17] S. SA, "Big Data in Healthcare Management: A Review of Literature," Am. J. Theor. Appl. Bus., vol. 4, no. 2, p. 57, 2018, doi: 10.11648/j.ajtab.20180402.14.

[18] J. Bicheno and M. Holweg, The Lean Toolbox, The essential guide to lean transformation. 2009.

[19] D. Hom, R. Perez, and L. Williams, "Which chart or graph is right for you ?," Tableau, 2014.

[20] Redding, Louis. (2014). Through-Life Engineering Services: Definition and Scope: A Perspective from the Literature. 10.1007/978-3-319-12111-6_2. 
2020-10-26

\title{
Methodology to identify and quantify sources of process scrap on shop floor
}

\author{
Alrufaihi, Duaa
}

SSRN

Alrufaihi D, Fernandes A, Gangar Jaysukh B, et al., (2020) Methodology to identify and quantify sources of process scrap on shop floor. In: TESConf 2020 - 9th International Conference on Through-life Engineering Services, 3-4 November 2020,Online, Cranfield, UK https://doi.org/10.2139/ssrn.3718046

Downloaded from Cranfield Library Services E-Repository 